\title{
DOL Factsheet: Paid Family and Medical Leave
}

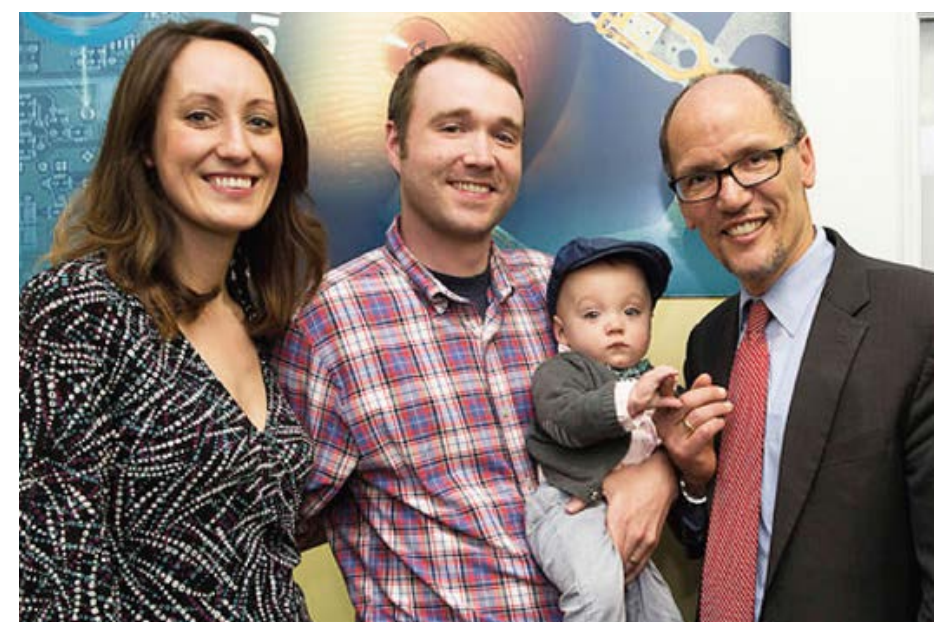

U.S. Secretary of Labor Thomas Perez and White House senior advisor Valerie Jarrett are traveling the country to highlight how states, localities and businesses are taking the lead on leave. Above, Secretary Perez meets with Anne Quirk, Griffin Quirk, and 10 month old Kiernan Quirk. The Quirk family was able to use paid leave to take care of their son Kiernan when he was sick.

The Obama Administration is committed to building opportunity for the middle class and an economy where all workers have a chance to realize their dreams. However, too many Americans cannot share in the nation's prosperity because they lack the basic supports they need to balance the demands of work and family. Strong paid family and medical leave policies can help working families take time off for caregiving responsibilities, as well as their own medical needs, without putting their economic security at risk. In addition, research has shown that paid family and medical leave policies have significant positive benefits for working families, employers, and the economy.

\section{The Need for Paid Leave:}

- Only 12 percent of U.S. private sector workers have access to paid family leave through their employer.

- Too many workers still cannot afford to take unpaid leave because of the loss of income it entails, or have to cut their leave short because of financial or workplace pressures.

- Millions of workers have caregiving responsibilities for both young children and aging parents.

\section{The Benefits of Paid Leave:}

- Paid maternity leave can increase female labor force participation by making it easier for women to stay in the workforce after giving birth, which contributes to economic growth. When parents are better supported at work through paid family and medical leave, they are also less likely to rely on public assistance benefits.

- Paid leave leads to better outcomes for parents and children. Maternity leave improves child health outcomes, including increased birthweight, decreased premature births and decreased infant mortality. Paid leave encourages men to take paternity leave and serve as caregivers, which has a number of positive effects for families.

- Paid maternity leave increases worker retention and reduces turnover, saving businesses significant costs associated with replacing employees. After California and New Jersey enacted paid family leave benefits, most businesses in those states reported positive or neutral experiences and few negative effects.

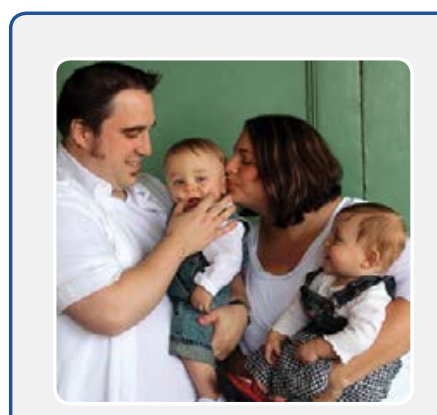

Fewer Worries Thanks to New Jersey's Paid Leave "The day that Jack and Ava were born, we had nothing. No baby shower, no cribs, no names... they were born a little over two and a half months early. We spent 69 days in the Neonatal Intensive Care Unit... and had time to get all the essentials together before they came home. Because New Jersey has paid family leave, we were able to focus on their needs for the first six months, and didn't have to worry about losing a paycheck."

- Jason Butkowski, New Jersey, on how paid leave
made a huge difference for his family.

\section{The Obama Administration is committed to Expanding Access to Paid Leave:}

- The President's 2016 budget will include more than $\$ 2$ billion in new funds to encourage States to develop paid family and medical leave programs.

- In 2015, the Department of Labor will award \$1 million for a grant program to help States, municipalities and federally recognized tribes conduct feasibility studies for paid leave programs.

This investment is in addition to the $\$ 500,000$ in grants the Department's Women's Bureau awarded in 2014 to three States and the District of Columbia. The Department of Labor is investing in research and analysis that will help State and local policy makers design the best possible paid leave programs.

\section{Get the Facts on PAID LEAVE}

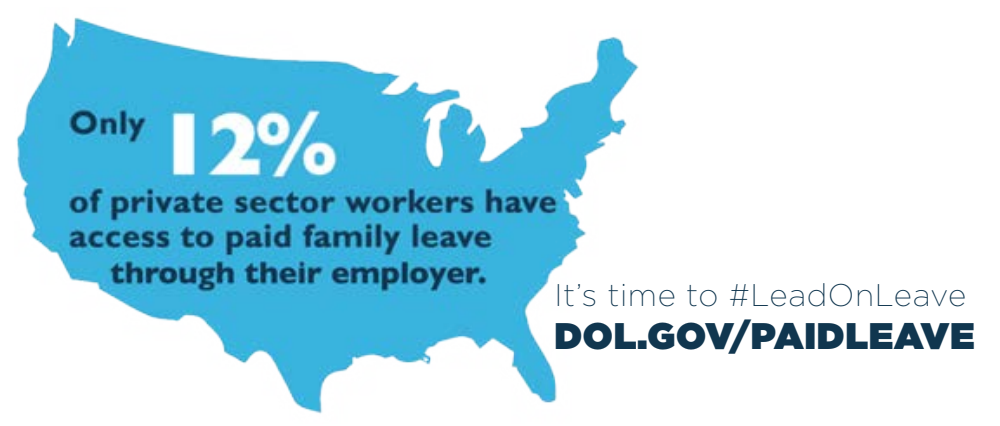

